\title{
Assessing slope failure of soil erodibility problem by soil dispersive identification
}

\author{
Reza Pahlevi Munirwan ${ }^{1 *}$, and Munirwansyah Munirwansyah ${ }^{1}$ \\ ${ }^{1}$ Department, of Civil Engineering, Universitas Syiah Kuala, Jl. Tgk. Syech Abdur Rauf No. 7 \\ Banda Aceh, Aceh 23111, Indonesia
}

\begin{abstract}
Dispersive soils are becoming a common building material. Due to their susceptibility to internal erosion and leakage, dispersive soils should only be used in combination with precise engineering measures to avoid catastrophic failures. Dispersive soils stabilization is critical and has been investigated in several studies conducted throughout the world. Erosion is a significant issue in structures built on sloping contours. As was the case with St. 670+250 Lipat Kajang road in Aceh Singkil. Soil erosion happens as a result of water's dispersion and transport force. Dispersive soil is one of the factors that contribute to an increase in the soil erodibility index. The objective of this research is to develop a method for enhancing the soil's dispersive qualities. In this investigation, specimens were prepared in three different soil mix plans $(10 \%$, $20 \%$, and $30 \%$ ) and then tested using a pinhole. The quantity of erodibility that happens in Sta. $670+250$ Lipat Kajang - Aceh Singkil Regency is based on the results of testing the soil's dispersive properties because the soil in this area is highly dispersive.
\end{abstract}

\section{Introduction}

Soil instability must be considered in road-building plans, even more so if the road is built on a sloped topography. One of the issues that can contribute to slope soil instability is the dispersive nature of the soil [1]. As a tropical country, Indonesia has a high risk of geological disasters and landslides each year, particularly during the rainy season [2] and [3]. The Indonesian government has made measures to mitigate the risk of road damage, including enhancing road geometry, reinforcing slopes, and rehabilitating eroded soil [4] and [5]. However, this appears insufficient to address road slope degradation, as field evidence indicates that cracks and landslides caused by erosion continue to occur on the surface of road slopes [6]. Therefore, soil dispersive contributing to slope erodibility should also be evaluated as a possible cause of road collapse [7].

Dispersive soils are a type of problematic soil frequently encountered in engineering projects throughout several countries and geographical areas [1]. Alluvial soils formed by the deposition of mudrocks in aquatic environments are well-known to be dispersive. Still, soils formed by the weathering of metamorphic and igneous rocks are less dispersive and are typically non-dispersive [8]. In dispersive soils, repulsive forces between clay particles are greater than clay particles attractive forces, resulting in a poor and unstable soil structure. These soils are prone to erosion. Even exposure to a modest flow can readily result in particle separation from the soil structure and erosion of the soil [9].
Due to the high cost of repairing significant earth constructions, substantial effort has been directed to various techniques of soil treatment [5] [10] and [11]. The simplest engineering solution for avoiding difficulties related to dispersive soils is to replace them with another soil [1]. However, this technology has limitations in terms of project economics. In addition, in many circumstances, soil remediation has been regarded as a more practical choice.

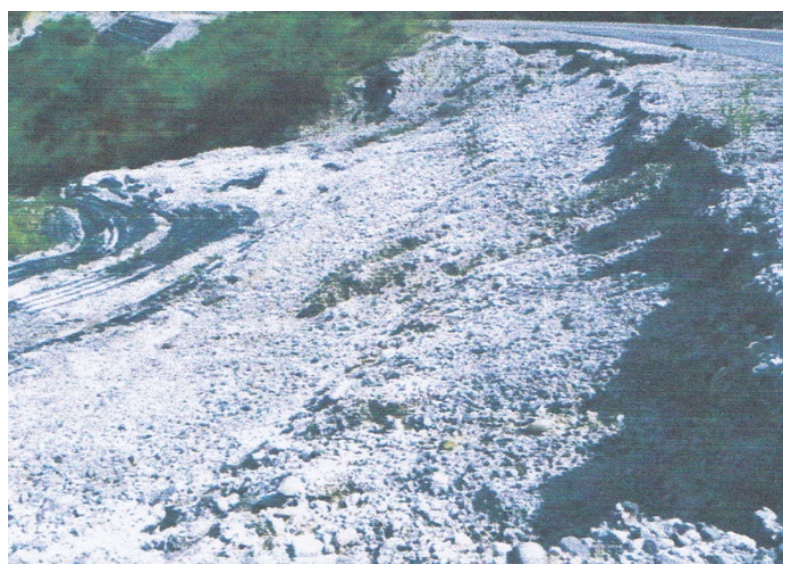

Fig. 1. Lipat Kajang Road - Aceh Singkil Regency Destruction

This study aims to ascertain whether or not the soil along the slope of the Lipat Kajang road segment in Aceh Singkil is dispersive (figure 1). Additionally, it is vital to determine the best ways to stabilize or improve the soil's dispersive qualities on road slopes.

\footnotetext{
* Corresponding author: r.munirwan@unsyiah.ac.id
} 


\section{Study Literature}

Soil erosion is a natural disaster and physical phenomenon that can cause significant harm to both humans and the environment [1]. It severely impacts farmland, civil engineering structures, and cutting subsurface pipelines or cables exposed. Furthermore, soil erosion worsened structural engineering difficulties such as landslides, ground subsidence, and bank failures, culminating in disastrous and permanent losses. Due to soil erosion, the most common structural collapses are piping collapses and slope erosion due to rainfall [12].

From [13], an investigation of several soil indices as indications of excessive soil erodibility in Anambra State, south-eastern Nigeria, examines the topic through the perspective of soil indices. The study discovered soil characteristics by investigating soil samples collected from several study regions and their varying degrees of prediction and contributing to soil erodibility within the work area. The study of soil data indicates that the soils in the survey area are very erodible and susceptible to erosivity at dispersion rates (DR) ranging around 0.429 $0.865 \%$ assuming that soils with a dispersion rate higher than $0.15 \%$ are naturally erodible. In addition, soils with a low organic matter concentration are more prone to erosive soil conditions.

The research from [14] primary purpose was to investigate the erosion tendency of compacted biochar amended soil (BAS) derived from four unique biochars. Biochar was manufactured in-house and combined with soil at $5 \%$ and $10 \%$ concentration of the weight. Eightyone pinhole erosion trials were performed in total to determine the rate of erosion of bare soil and BAS at three various compaction stages using the same amount of compaction energy. It was discovered that the erosion rate decreased as the water content increased gradually for BAS, which was ascribed primarily to the particles changing direction from flocculated to scattered along the compaction curve. The application of biochar to soil decreased erosion in the dry condition and increased wet state erosion.

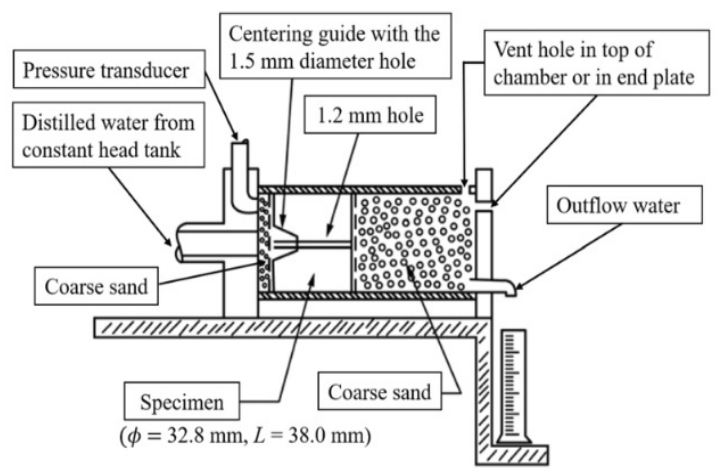

Fig. 2. Diagrammatic representation of the pinhole test equipment [12]

[15] conducted a review of the literature on soil erosion trends, conflicts, and perspectives in the context of South African. Additionally, the feasibility of employing the link between aggregate erodibility and stability as an indicator of soil erosion susceptibility was studied. This connection is frequently utilized in place of time-consuming and costly local soil erosion investigations and models. However, there are conflicting reports on its potential to provide rapid data regarding the soil's vulnerability to erosion. Nevertheless, a review of the South African and international references revealed that aggregate stability is a commonly used physical measure of soil erodibility. Nonetheless, there is no consensus regarding the most appropriate aggregate stability measures to utilize.

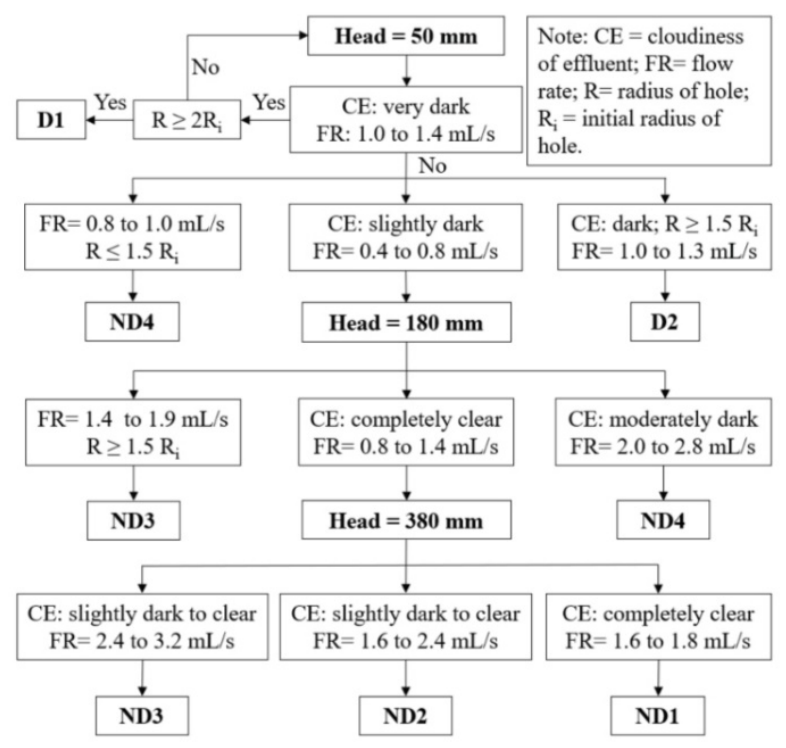

Fig. 3. Procedure for conducting pinhole tests and classification scheme [12]

[16] provides a comprehensive overview of current knowledge and experiences on core soil filtration, especially dispersive soils. The engineering challenges related to dispersive soils are also explored, and fundamental discoveries from past research on protective filters. It is worth noting that the current review considers both traditional, more empirical filter design criteria based on particle sizes and the current, more conceptual state-of-the-art filter specifications. That is based on constriction sizes, with the discussion of their respective pros and contras. This review's knowledge should help investigate, plan, and operate associated geoenvironmental and geotechnical projects.

\section{Methods}

Numerous studies have been undertaken to determine the erodibility of soils using various instruments and testing methods, including the crumb test, pinhole test, jet erosion test, hole erosion test, flow pump test, and flume erosion test. Among these tests, the pinhole test is widely recognized as the most trustworthy for classifying and identifying soil erodibility. It directly assesses the erodibility and dispersibility of the soil due to the water flowing through a small hole in the middle of the soil sample (figure 2). The advantage of this method is the small sample size required, the ease with which the sample is prepared, and the straightforward testing technique. The procedure for conducting pinhole tests and classification schemes can be seen in figure 3 . 
Table 1. Mixing presentation of soil specimens

\begin{tabular}{|c|c|c|}
\hline $\begin{array}{c}\text { Specimens } \\
\text { Code }\end{array}$ & $\begin{array}{c}\text { Lipat } \\
\text { Kajang } \\
\text { Soil } \\
\text { (\%) }\end{array}$ & $\begin{array}{c}\text { Gle } \\
\text { Geunteng } \\
\text { Soil } \\
\text { (\%) }\end{array}$ \\
\hline LK & 100 & - \\
\hline $\mathrm{LG}_{10}$ & 90 & 10 \\
\hline $\mathrm{LG}_{20}$ & 80 & 20 \\
\hline $\mathrm{LG}_{30}$ & 70 & 30 \\
\hline
\end{tabular}

This research approach was designed by reviewing the subject matter and literature studies, and other comparable references. The soil sampled for this study is from the slopes of the Lipat Kajang road, which connects Lipat Kajang Sta. $670+250$ to Aceh Singkil Regency. Additionally, soil stabilization measures will be made using clay Gle Geunteng Village in the Peukan Bada District of Aceh Besar. This research sampled is disturbed soil. The soil specimens of the mixing presentation are shown in table 1.

Table 2. Result of flow rate and hole size after tests from different water level experiments.

\begin{tabular}{|c|c|c|c|c|}
\hline \multirow[t]{2}{*}{ Sample } & $\begin{array}{c}\text { Diff. } \\
\text { Water } \\
\text { Level }\end{array}$ & Time & $\begin{array}{l}\text { Flow } \\
\text { Rate }\end{array}$ & $\begin{array}{l}\text { Hole size } \\
\text { after tests }\end{array}$ \\
\hline & $(\mathrm{mm})$ & (second) & $(\mathrm{ml} / \mathrm{s})$ & $(\mathrm{mm})$ \\
\hline \multirow{3}{*}{ LK } & 50 & 5 & 1.20 & $4.0-4.5$ \\
\hline & 50 & 5 & 1.36 & $3.5-4.0$ \\
\hline & 50 & 5 & 1.50 & $3.5-4.0$ \\
\hline \multirow{3}{*}{$\mathrm{LG}_{10}$} & 50 & 10 & 1.13 & $1.5-2.0$ \\
\hline & 50 & 10 & 1.11 & $1.5-2.0$ \\
\hline & 50 & 10 & 1.08 & $2.0-2.5$ \\
\hline \multirow{3}{*}{$\mathrm{LG}_{20}$} & 50 & 10 & 0.87 & $1.0-1.5$ \\
\hline & 50 & 10 & 0.90 & $1.0-1.5$ \\
\hline & 50 & 10 & 0.92 & $1.5-2.0$ \\
\hline \multirow{3}{*}{$\mathrm{LG}_{30}$} & 180 & 5 & 1.50 & $2.5-3.0$ \\
\hline & 180 & 5 & 1.40 & $3.5-4.0$ \\
\hline & 180 & 5 & 1.43 & $3.5-4.0$ \\
\hline
\end{tabular}

The purpose of this research is to conduct geotechnical investigations on the erodibility of soils, utilizing a pinhole test to determine soil dispersive qualities. The test object, specifically the original soil combined with varying percentages of clay, will be modeled. The specimens were made according to the various clay addition plans $(10 \%, 20 \%, 30 \%)$ and then molded into test specimens with a diameter (d) of 32.5 $\mathrm{mm}$ and a length (L) of $37.5 \mathrm{~mm}$.
Testing with pinhole instruments at $50 \mathrm{~mm}, 180 \mathrm{~mm}$, $380 \mathrm{~mm}$, and $1020 \mathrm{~mm}$ water height differences. Results of flow rate and hole size after tests from different water level experiments can be seen in table 2 . The investigation was conducted in ascending order. The results collected during the laboratory identification of the dispersive qualities of soil using pinholes will be classed as D1 (highly dispersive), D2 (dispersive), ND4 (possibly dispersive), ND3 (possibly dispersive), ND2 (not dispersive), and ND1 (not dispersive). After determining the soil's dispersive qualities on the natural soil, specimens were modeled by combining the soil sample (Lipat Kajang + Glee Geunteng) with the specified percentage of the mixture.

\section{Results}

Soils with high clay content are generally more resistant to erosion than soils with low clay content. AASHTO classifies Lipat Kajang soil as group A-4(2), sandy, loamy silt, yellowish gray, whereas Glee Geunteng soil is classified as group A-7-6(31), reddish-brown silty clay. Based on the soil physical properties, the Lipat Kajang soil is more likely to be dispersive when compared to the Glee Geunteng soil. This is because the Lipat Kajang soil contains less clay than the Glee Geunteng soil. Therefore, for initial identification, the Lipat Kajang soil is identified as dispersive soil. Meanwhile, Glee Geunteng is categorized as nondispersive soils.

The findings of the pinhole test used to determine the soil's dispersive qualities are classified based on the difference in water level test time, flow rate, water turbidity, and hole diameter. The dispersive nature of the soil is one of the variables that contribute to the increase in the soil erodibility index. This is because dispersive soil is quickly scattered, particularly during the wet season.

Field evidence indicates that on the slopes of the Lipat Kajang road in Aceh Singkil Regency, small holes run with cloudy and hazy water caused by distributed soil particles. If it occurs on a large scale, it can result in a landslide, which is extremely dangerous for road users. Landslides on the slopes of the Lipat Kajang road in Aceh Singkil Regency are generally caused by the soil's incapacity to endure the destructive force of water, as the soil in the area is classified as type D1, a very dispersed soil classification. The result of dispersive soil classification can be seen in table 3 .

\section{Conclusions}

Based on the findings of the tests, it can be stated that the lower the clay content of the soil, the greater the likelihood that the soil will be dispersive in nature. In Aceh Singkil Regency, a landslide occurred on the slopes of the Lipat Kajang road Sta. $670+250$, which occurred because the soil is very dispersive. Based on the findings of the pinhole test, it has been classified as D1. A mixture of 30 percent Glee Geunteng clay can improve the soil dispersive qualities on the slopes of the Lipat Kajang Sta. 670+250 Aceh Singkil District, 
bringing them from category D1 to ND3 which is not dispersive soil.

Table 3. The classification result of dispersive soil

\begin{tabular}{|c|c|c|c|}
\hline \multirow{2}{*}{ Sample } & \multicolumn{2}{|c|}{$\begin{array}{c}\text { End of test water } \\
\text { visual }\end{array}$} & \multirow{2}{*}{ Classification } \\
\hline & side & top & \\
\hline \multirow{3}{*}{ LK } & $\begin{array}{c}\text { Very } \\
\text { Cloudy }\end{array}$ & Cloudy & D1 \\
\hline & $\begin{array}{c}\text { Very } \\
\text { Cloudy }\end{array}$ & Cloudy & D1 \\
\hline & $\begin{array}{c}\text { Very } \\
\text { Cloudy }\end{array}$ & Cloudy & D1 \\
\hline \multirow{3}{*}{$\mathrm{LG}_{10}$} & Cloudy & Cloudy & D2 \\
\hline & Cloudy & Cloudy & D2 \\
\hline & Cloudy & Cloudy & D2 \\
\hline \multirow{3}{*}{$\mathrm{LG}_{20}$} & $\begin{array}{l}\text { Medium } \\
\text { Cloudy }\end{array}$ & Cloudy & ND4 \\
\hline & $\begin{array}{l}\text { Medium } \\
\text { Cloudy }\end{array}$ & Cloudy & ND4 \\
\hline & $\begin{array}{l}\text { Medium } \\
\text { Cloudy }\end{array}$ & Cloudy & ND4 \\
\hline \multirow{3}{*}{$\mathrm{LG}_{30}$} & $\begin{array}{l}\text { Slightly } \\
\text { Cloudy }\end{array}$ & $\begin{array}{l}\text { Medium } \\
\text { Cloudy }\end{array}$ & ND3 \\
\hline & $\begin{array}{l}\text { Medium } \\
\text { Cloudy }\end{array}$ & $\begin{array}{l}\text { Medium } \\
\text { Cloudy }\end{array}$ & ND3 \\
\hline & $\begin{array}{l}\text { Medium } \\
\text { Cloudy }\end{array}$ & $\begin{array}{l}\text { Medium } \\
\text { Cloudy }\end{array}$ & ND3 \\
\hline
\end{tabular}

\section{References}

1. A. Masoodi, M. R. M. Tabatabai, A. Noorzad, and A. Samadi, J. Hydrol. Eng. 24, (2019)

2. Munirwansyah, M. Irsyam, R. P. Munirwan, H. Yunita, and M. Zulfan Usrina, IOP Conf. Ser. Mater. Sci. Eng. 352, (2018)

3. M. Sungkar, M. Munirwansyah, R. P. Munirwan, and D. Safrina, IOP Conf. Ser. Mater. Sci. Eng. (2020)

4. M. Munirwansyah, R. P. Munirwan, and H. Yunita, Int. J. Adv. Sci. Eng. Inf. Technol. 8, 870 (2018)

5. R. P. Munirwan, M. Munirwansyah, M. Marwan, P. J. Ramadhansyah, and V. Kamchoom, IOP Conf. Ser. Mater. Sci. Eng. (2020)

6. B. Bin Xu and W. Si, Matec Web Conf. (2016)

7. A. Maharaj, L. Van Rooy, and P. Paige-Green, J. South African Inst. Civ. Eng. 57, 31 (2015)

8. S. Moravej, G. Habibagahi, E. Nikooee, and A. Niazi, Geoderma 315, 130 (2018)

9. A. Bernatek-Jakiel and J. Poesen, Earth-Science Rev. 185, 1107 (2018)

10. D. Sundary, R. P. Munirwan, and N. Al-Huda, J. Phys. Conf. Ser. (2021)

11. M. Munirwansyah, R. P. Munirwan, M. Sungkar, and F. Fachrurrazi, AIP Conf. Proc. 020029, (2019)

12. B. H. Dinh, A. D. Nguyen, S. Y. Jang, and Y. S.
Kim, Int. J. Geo-Engineering 12, (2021)

13. R. U. Ayadiuno and D. C. Ndulue, Int. J. Mod. Agric. 10, 3451 (2021)

14. H. Kumar, S. Prakash, S. Bordoloi, S. Sreedeep, P. Lin, G. Mei, A. Garg, and A. K. Sarmah, Sci. Total Environ. 672, 698 (2019)

15. A. D. Nciizah and I. I. C. Wakindiki, Arch. Agron. Soil Sci. 37 (2014)

16. A. H. Vakili, M. R. Selamat, P. Mohajeri, and H. Moayedi, Geotech. Geol. Eng. (2018) 